Research Article

\title{
CALL-Enhanced L2 Vocabulary Learning: Using Spaced Exposure through CALL to Enhance L2 Vocabulary Retention
}

\author{
Fidel Çakmak, ${ }^{1}$ Ehsan Namaziandost $\mathbb{D}^{2},{ }^{2}$ and Tribhuwan Kumar ${ }^{3}$ \\ ${ }^{1}$ Alanya Alaaddin Keykubat University, Antalya, Turkey \\ ${ }^{2}$ Department of English, Islamic Azad University, Shahrekord Branch, Shahrekord, Iran \\ ${ }^{3}$ Prince Sattam Bin Abdulaziz University, Al Kharj, Saudi Arabia \\ Correspondence should be addressed to Ehsan Namaziandost; e.namazi75@yahoo.com
}

Received 3 July 2021; Accepted 27 August 2021; Published 16 September 2021

Academic Editor: Enrique Palou

Copyright ( 2021 Fidel Çakmak et al. This is an open access article distributed under the Creative Commons Attribution License, which permits unrestricted use, distribution, and reproduction in any medium, provided the original work is properly cited.

CALL- and MALL-enhanced learning applications have dominated the field of second language (L2) learning recently. This study aims to investigate the effect of applying a CALL-enhanced L2 vocabulary learning software program on the L2 vocabulary development of English as Foreign Language (EFL) students. 76 preintermediate EFL students registered at a foreign language school were chosen from a total of 156 students after running an Oxford Quick Placement Test (OQPT). The participants were randomly assigned to two groups: the experimental group $(E G=38)$ and the control group $(C G=38)$. A vocabulary test as pretest was administered to all the participants before the treatment. During the treatment, the EG learners were requested to utilize a computer-enhanced flashcard software program on their laptops, mobile phones, or other mobile devices at their discretion. By using the program, they could access and utilize a variety of flashcards on many subject matters such as languages, geography, math, and science as well as construct their own flashcards for multiple practices. The CG, on the other hand, was taught through traditional teaching without any CALL tools available. At the termination of the intervention, the vocabulary test was employed as a posttest to both groups to assess the learners' vocabulary enhancement. The EG outperformed the CG. Findings have led to the reasonable interpretation that L2 vocabulary learning was more productive when the CALL-enhanced flashcard program was utilized for the learning processes.

\section{Introduction}

All human activities, particularly education, are affected by technology. Computers have become integral to our daily lives. Of late, computer-aided vocabulary learning has gained interest of instructors and scholars and has been recognized as one of the most important examples of CALL. Computers can be regarded as a modern beneficial instrument for vocabulary teaching in educational environments.

The most popular word utilized by instructors and learners to explain the usage of computers in language classes is CALL [1]. While CALL seems to be a newer addition to language education, it has developed over decades. The practice of CALL dates to the 1960s, and its progress has been enthusiastically followed by researchers since that time.

With the expanded usage of computers in language learning, the learner's choice of what vocabulary to learn has become increasingly important [2]. Using programs like HyperCard or Tool Booklet, teachers develop hypertexts which are texts connected to other texts within the computer, which can be dictionaries, thesauruses, or images $[3,4]$. Students may use these hypertexts to clarify context and usage of vocabulary. In this case, a pop-up dictionary appears when a learner clicks on a phrase or pushes the key specified in the curriculum, offering the meaning, grammar, and cultural usage context. Using a computer, the student can also quickly search for words by accessing a dictionary, thesaurus, or broad-term archive.

CALL covers an extensive variety of implementations and strategies in foreign language learning (FLL) and instruction, from the mechanical drills that dominated the early years of CALL implementations to more modern iterations of CALL, which involve interactive or smart learning environments and are accessible through mobile 
platforms. These implementations and strategies can facilitate the use of authentic target language resources and aid in clarifying colloquial expressions, as well as offering digital whiteboards and other resources. Computer technology, according to several scholars, is the perfect method for enhancing students' English learning. CALL is described by Hubbard [5] as "any approach in which a student utilizes a computer to develop his or her language skills." (p.10). The emergence of CALL, according to Tabar and Khodareza [6], offered new perspectives into L2 vocabulary learning. The effect of CALL on L2 vocabulary development is important according to numerous language researchers [7-10]. Whether or not to use computer-mediated technologies in educational contexts is not the key issue; rather, teachers must consider how CALL can better be extended to improve the delivery of meaningful language teaching to students $[11,12]$. It is widely accepted that L2 vocabulary learning is essential in foreign language learning [13]. According to Xu [14], vocabulary is fundamental to interaction, and the necessity of acquiring vocabulary is a view shared by both teachers and students. When learners lack sufficient vocabulary, communication breaks down, and this leads us to consider L2 vocabulary acquisition as crucial for productive skills. As a result, for most EFL students, mastering a language mainly involves mastering its vocabulary $[15,16]$.

To be more specific, vocabulary is regarded as mandatory to acquiring knowledge through receptive skills, reading and listening, and essential to the development of the productive skills of communicating and writing. The primary objective of using visual support for the instruction of vocabulary materials, according to Hsieh [17] and Wright [18], is to help the student better understand and retain new words. Visual aids are useful as they enable students to easily access and share knowledge and can facilitate the understanding of otherwise inscrutable new vocabulary.

Traditional school environments and classrooms in the EFL context require the students to be on the same page with their textbooks, strictly following what teachers instruct. The class normally reads the passages in the textbooks together and silently, often stopping midreading to discuss relevant details. This style of instruction can disengage the student from the actual cognitive reading process and inhibit autonomous learning.

Thanks to emerging technologies and the development of CALL and MALL studies, there are now different innovative ways to learn languages. These developments have given students extensive opportunities to learn an L2 language and enjoy the flexibility of learning and practice whenever they have access. In some contexts, barriers of affordances of the digital environment concerning cost and accessibility remain.

While some students of foreign language learning praise the merits of CALL or MALL for enhanced second language learning, some still believe deeply in the habitual use of books for practical reasons. However, as we witness the fact that most work is performed through computers, teachers, students, and education policy planners should try to find a way to incorporate the advantages of recent technical developments [19] in their curricula. Another barrier to consider when implementing technology-enhanced learning, unfortunately, is that there is a fragmented array of language learning software and resources for different profile of users, which have little basis of comparison with each other as they vary in function, interface, designs, and prerequisite skills. Unguided learners might feel lost in the array of opportunities and may choose to stick to what is familiar. Moreover, in some contexts, the assessment and validation instruments for evaluating and standardizing components of the software are open for discussion $[20,21]$. These are basic concerns that can require teachers to select certain CALLenhanced programs in their classes, and it is paramount for solid implementation of CALL or MALL that the chosen programs fit the actual needs of the learners in a particular context of teaching.

With this in mind, the current research will address topics raised in the recent years: does technology-enhanced implementation boost language learning? This research tries to determine if the teaching of L2 skills and components is accomplished more effectively with books or with a specific piece of software. The interest in this field of language learning is of particular significance to the discussion of cognitive processes in learning and how memory works and how to integrate cognitive learning processes with curricula, use of technology and language methodology for more effective learning results. One memory technique is spaced repetition which can help the student to memorize several small and autonomous information bits by maximizing the quality of recall of L2 language input as a process and reducing the time to complete the task. It is a technique meant for enhanced long-term learning of discrete parcels of information; after several weeks or months of work, the target data can be quickly recalled. Other less efficient techniques are more demanding and require even more time and energy to master a set of information. Spaced repetition is not ideal, however, for the learning of dynamic content, which cannot be easily parsed into smaller units efficiently.

Some earlier studies have identified the utilization of computer-mediated language learning as a good medium for long-term learning. Spaced repeating can assist users in building effective study patterns with an application while engaged in L2 learning [22-27]. Other studies showed more innovation, such as how to teach vocabulary to students by making lists of words more powerful and interesting through multimedia enhancement, and this was particularly applied to the English language [28-30]. Pedagogically, spaced repeats delivered over time through technologyenhanced implementations are suggested as helpful and effective for learning L2 vocabulary [31]. Moreover, teaching with flashcards and text lists does improve student vocabulary [32]. Wordlists can help both English teachers and students to understand and produce English vocabulary [33]. Giving students just 10 minutes of vocabulary learning enhances the drive of the student to learn and leads them to spend more time studying vocabulary [34]. The abovementioned results showed interesting results regarding the willingness of students to learn English. The research focused on improving the language use of English by incorporating various media and teaching techniques. In this 
analysis, the researchers have used CALL-enhanced language learning to develop students' L2 vocabulary capacity.

The challenge that educators and learners understand is that learners do not readily learn or remember vocabulary for a long time or easily recall the information when necessary. Teachers may use different classroom methods, such as drawing images, diagrams, tables, charts, synonyms, symbols, mimics, and acting, to inspire students and to help them master a language successfully. Despite this, it is difficult for students to master a second language. A qualified English speaker has been estimated to know approximately 17,000 basic words and has acquired them at speeds of two or three words daily [35]. Goodfellow further notes that the speed is a four-year total time undertaking for an English student to be able to read a magazine and another 13 years to become fully fluent. Learning vocabulary is essential, but it is also complex and time-consuming. Time and perseverance are required for both teachers and students. Beyond the L2 learning context, Kirsch [36] notes that a significant aspect of one's vocabulary is the amount of vocabulary exposure one has had. Vocabulary learning is an indispensable part of second and foreign language proficiency for many researchers [37-40]. The absence of vocabulary is a significant obstacle to successfully using a second language [41]. On this topic, learning L2 vocabulary has attracted interest. The scholars are concerned with how students can use vocabulary accurately and effectively. Understanding a term for Nation [42] means understanding its "form," "meaning," and "use" (p. 27). The traditional approach of rote memorization is not an easy or efficient way to learn vocabulary. In this case, a new approach or technique is tried which uses technology for EFL university students as an enhancement tool for vocabulary learning.

After establishing the need for vocabulary learning in language learning, another point to highlight is the importance of teaching strategies. Nagy et al. [43] suggest that vocabulary instruction that enhances understanding has certain features: numerous presentations of taught terms, exposures to those terms in relevant situations, access to a wealth of information about any term, and establishing relations between new words the student's previous knowledge (p. 33). If educators are well-versed about how a word is presented and what function it performs, they can help learners develop lexical knowledge by utilizing more effective word teaching strategies. Context-dependent vocabulary exercises which involve discerning text definitions in context, practice with memorization methods, using audiovisual aids, presenting vocabulary in different linguistic settings, incorporating themes, using mixed a methodology, and understanding the meanings of word structure and root origins are examples of such methods.

All in all, reviewing the literature so far indicates that the impact of CALL-based instruction on language skills and subskills has not received as much attention as warranted. A few studies have been done on using some CALL-based software programs for learning L2 vocabulary in the EFL context [44-46]. Inspired by these works, this study is an implementation of the CALL-enhanced L2 vocabulary learning in a different context and with low-proficiency participants. Researchers aim to explore if there was significant L2 vocabulary growth in a CALL context for these students as has been found in previous studies and to contribute to the field either supporting or rejecting the existing studies with empirical results. Thus, the principal aim of the current study is to see how beneficial CALLenhanced L2 vocabulary flashcard software is in supporting EFL students to enhance their vocabulary. It is necessary to keep in mind that software language learning is marked as CALL-enhanced L2 learning software. Two research questions were raised in this research:

RQ 1: does the use of CALL-enhanced L2 vocabulary learning software have any significant effect on L2 vocabulary learning?

RQ 2: are there any significant differences between CALL-enhanced L2 vocabulary learning and traditional L2 vocabulary learning?

\section{Method}

2.1. Participants. To conduct this research, 76 preintermediate EFL students were chosen from registered 108 EFL learners at a foreign language school in Turkey. These studies receive compulsory language training before they study at their programs. They have five hours of English scheduled every day from Monday to Friday and follow set course books in the classes. Participants' age range was between 18 and 20. Oxford Quick Placement Tests (OQPT) was utilized to determine the participants' entry level of English language proficiency before the treatment. Also, for the participant selection, the convenience sampling approach was adopted to simplify the research consent procedures and accessibility to the participants. The students were randomly placed into two equal size groups noted as the EG and the CG. Each group had 38 participants.

2.2. Instruments. A proficiency test was the first tool used in the current investigation to homogenize the subjects. The OQPT was given to 108 participants to identify their English language proficiency. According to OQPT standards, scores of 30 to 34 (out of 60) are classified as the preintermediate level [47]; participants at this level were chosen for this study.

2.3. Vocabulary Pretest and Posttest. A researcher-constructed vocabulary pretest was utilized as the second instrument in this project. It comprised an 80-item multiplechoice $(\mathrm{M} / \mathrm{C})$ test. At another language institute, the vocabulary test was piloted with 40 respondents. Inappropriate items were corrected based on item analysis of the obtained data. The Cronbach alpha reliability of the pilot test was 0.989 . The validity of both pre- and posttests was checked statistically by a panel of English experts.

2.4. The Mnemosyne Software. The Mnemosyne program is an outcome of the project and runs as a flashcard program that aids in learning specific subject matters and general 
world knowledge through custom flashcards. It provides a flashcard application that enables interactions between the learner (students in this context) and the interface. Two types of cards can be produced by Mnemosyne entry: a recognition card that shows the students the equivalent of the term in different language selected and a production card that enables students to seek that term in foreign language. Cards can be exhibited in terms of their production date. The Mnemosyne technically provides multiple exposures to their academic vocabulary through practice, keeping the cards and records of their usage in logs. According to prior investigations in both memory and second language acquisition, spaced repetition, exposure to the learning material with time intervals, rather than massed repetition, seems to be more effective in terms of facilitating long-term knowledge storage [48]. To avoid typical forgetting, scheduled review sessions on the program help students to retain target phrases for practice at intervals. By using such a CALL-enhanced L2 vocabulary learning program with scheduled reviews, students can better develop L2 vocabulary learning when compared to other traditional flashcard methods.

2.5. Data Collection Procedure. The current study's target group comprised 76 individuals. Prior to the treatment, participants signed a consent form and completed a pretest to assess their knowledge of vocabulary. Then, they were randomly put into two groups: either EG or CG. The subjects in the EG were given vocabulary instruction utilizing Mnemosyne software, which allowed them to see the texts with both static and dynamic images associated with the words. It was made available to them on their computers, laptops, or other gadgets such as a tablet or mobile phone. Participants could also construct custom electronic cards with question and response and enhance them with multimedia enrichment such as picture and sound. The study's target vocabulary terms were selected from an academic word list [49]. For the current research, an academic vocabulary dictionary with 300 academic terms was created, and students utilized Mnemosyne for 10 minutes every day for 7 weeks as one of their weekly assignments in their English course. The CG taught the same vocabulary using the traditional techniques within the same amount of time. This included the use of equivalent meaning in L1, translations, sample sentence writing, and so forth. All other procedures were the same in both groups with the only pedagogical variable being that the EG group had access to the CALL-enhanced L2 vocabulary tool to learn and practice L2 vocabulary. To measure their vocabulary growth, all participants performed a posttest at the end of the intervention that encompassed all the vocabulary items presented during the course.

\section{Results}

To determine the normality of the distributions of test scores, the Kolmogorov-Smirnov test was computed. Table 1 displays the outcomes.
TABLE 1: Normality test for the scores of the pretest and posttest.

\begin{tabular}{lccc}
\hline & \multicolumn{3}{c}{ Kolmogorov-Smirnov $^{\mathrm{a}}$} \\
& Statistic & $\mathrm{d} f$ & Sig. \\
\hline EG pretest & 0.172 & 38 & 0.09 \\
EG posttest & 0.215 & 38 & 0.11 \\
CG pretest & 0.195 & 38 & 0.07 \\
CG posttest & 0.196 & 38 & 0.11 \\
\hline
\end{tabular}

$p<0.05$.

As seen in Table 1, the distributions of test scores were normal. As a follow-up of analysis procedures, researchers checked the homogeneity of the two groups' L2 vocabulary knowledge. As a result, their pretests were compared using an independent-samples $t$-test.

Table 2 reveals that the mean pretest score for EG was 15.76, whereas the mean score for CG was 15.44. The researchers checked the $p$ value in the $t$-test table to see if there was any statistically significant difference between the two groups on the pretest.

As presented in Table 3, both groups had similar levels of L2 vocabulary knowledge before the intervention.

The posttest scores of the EG and CG learners were also analyzed. To compare their posttest results, one-way ANCOVA was computed.

Table 4 shows that the EG learners' posttest mean score $(M=31.05)$ was higher than the CG learners' posttest mean score $(M=16.18)$. The researchers also calculated the sig. value and presented the findings about the first research question in Table 5.

As Table 5 demonstrates, the difference on the vocabulary posttest between the two groups of EG $(M=31.05)$ and CG $(M=16.18)$ was statistically significant. This indicates that utilizing the Mnemosyne program might have greatly facilitated EG learners' L2 vocabulary learning. Table 5 also includes the effect size (0.87), indicating that the treatment (using the Mnemosyne software) accounted for 87 percent of the difference between the EG and CG learners.

To answer the second research question of this study, the pretest and posttest scores of the students in both groups were compared statistically.

According to Table 6, the CG students received mean scores of 15.44 on the L2 vocabulary pretest and 16.18 on the posttest. Furthermore, the descriptive statistics in Table 6 show that the EG learners progressed from a mean score of 15.76 on the pretest to a mean score of 31.05 on the posttest. The paired samples $t$-test table is presented in Table 7 .

Table 7 demonstrates that the difference between the EG learners' L2 vocabulary pretest $(M=15.76)$ and posttest $(M=31.05)$ was statistically significant. The finding suggests that CALL-based instruction has a substantial impact on the L2 vocabulary development.

\section{Discussion and Conclusion}

As affirmed by the outcomes of statistical analyses, the CALL-enhanced L2 vocabulary learning software program was found to be more effective for EFL learners. The study's findings offer empirical evidence for the superiority of 
TABle 2: Descriptive statistics for the pretest.

\begin{tabular}{lccccc}
\hline & Groups & N & Mean & Std. deviation & Std. error mean \\
\hline \multirow{2}{*}{ Pretest } & EG & 38 & 15.76 & 1.45 & 0.23 \\
& CG & 38 & 15.44 & 1.51 & 0.24 \\
\hline
\end{tabular}

TABLE 3: Independent samples $t$-test (pretest scores of EG and CG).

\begin{tabular}{|c|c|c|c|c|c|c|c|c|c|c|}
\hline & & $\begin{array}{r}\text { Lev } \\
\text { tes } \\
\text { equa } \\
\text { vari }\end{array}$ & $\begin{array}{l}\text { he's } \\
\text { for } \\
\text { ty of } \\
\text { hces }\end{array}$ & & & $t$-test $f$ & equality of & neans & & \\
\hline & & $\mathrm{F}$ & Sig. & $t$ & $\mathrm{~d} f$ & Sig. (2-tailed) & $\begin{array}{c}\text { Mean } \\
\text { difference }\end{array}$ & $\begin{array}{l}\text { Std. error } \\
\text { difference }\end{array}$ & $\begin{array}{r}95 \% \text { co } \\
\text { interv } \\
\text { diffe }\end{array}$ & $\begin{array}{l}\text { fidence } \\
\text { of the } \\
\text { ence }\end{array}$ \\
\hline & & & & & & & & & Lower & Upper \\
\hline Pretest & Equal variances assumed & 0.66 & 0.41 & 0.92 & 74 & 0.35 & 0.31 & 0.34 & -0.36 & 0.99 \\
\hline Pretest & Equal variances not assumed & & & 0.92 & 73.88 & 0.35 & 0.31 & 0.34 & -0.36 & 0.99 \\
\hline
\end{tabular}

$p<0.05$.

TABLE 4: Descriptive statistics for the posttest.

\begin{tabular}{lccc}
\hline Groups & Mean & Std. deviation & N \\
\hline EG & 31.05 & 2.72 & 38 \\
CG & 16.18 & 2.89 & 38 \\
Total & 23.61 & 7.98 & 76 \\
\hline
\end{tabular}

TABLE 5: Results of one-way ANCOVA (posttest of EG and CG).

\begin{tabular}{lcccccc}
\hline Source & Type III sum of squares & $\mathrm{df}$ & Mean square & F & Sig. & Partial eta squared \\
\hline Corrected model & 4216.37 & 2 & 2108.18 & 271.15 & 0.00 & 0.88 \\
Intercept & 234.82 & 1 & 234.82 & 30.20 & 0.00 & 0.29 \\
Pretest & 16.04 & 1 & 16.04 & 2.06 & 0.15 & 0.00 \\
Groups & 4097.48 & 1 & 4097.48 & 527.02 & & \\
Error & 567.55 & 73 & 7.77 & & & \\
Total & 47179.00 & 76 & & & \\
Corrected total & 4783.93 & 75 & & & \\
\hline
\end{tabular}

$p<0.05$.

TABLE 6: Results of descriptive statistics (pretest and posttest of EG and CG).

\begin{tabular}{lccccc}
\hline & & Mean & N & Std. deviation & Std. error mean \\
\hline \multirow{2}{*}{ Pair 1} & EG post & 31.05 & 38 & 2.72 & 0.44 \\
& EG pre & 15.76 & 38 & 1.45 & 0.23 \\
\hline \multirow{2}{*}{ Pair 2} & CG post & 16.18 & 38 & 2.89 & 0.46 \\
& CG pre & 15.44 & 38 & 1.51 & 0.24 \\
\hline
\end{tabular}

TABLE 7: Paired samples $t$-test (pretest and posttest of EG and CG).

Paired differences

\begin{tabular}{|c|c|c|c|c|c|c|c|c|c|}
\hline & & \multirow[t]{2}{*}{ Mean } & \multirow[t]{2}{*}{ Std. deviation } & \multirow[t]{2}{*}{ Std. error mean } & \multicolumn{2}{|c|}{$\begin{array}{l}\text { 95\% confidence } \\
\text { interval of the } \\
\text { difference }\end{array}$} & \multirow[t]{2}{*}{$\mathrm{T}$} & \multirow[t]{2}{*}{$\mathrm{d} f$} & \multirow[t]{2}{*}{ Sig. (2-tailed) } \\
\hline & & & & & Lower & Upper & & & \\
\hline Pair 1 & EG post-EG pre & 15.28 & 3.17 & 0.51 & 14.24 & 16.33 & 29.65 & 37 & 0.00 \\
\hline Pair 2 & CG post-CG pre & 0.73 & 2.70 & 0.43 & -0.15 & 1.62 & 1.67 & 37 & 0.11 \\
\hline
\end{tabular}


computerized flashcard teaching methods on L2 vocabulary learning among EFL learners when compared to traditional methods.

The experiment group's performance on L2 vocabulary tests can be explained by some significant factors. During the implementations, the students had more control over their learning. This autonomous learning might have encouraged motivation and sense of agency among the students $[10,50,51]$. Another factor is the one-on-one interactions between students and computers, which may also facilitate better L2 vocabulary learning [52]. It could be that the computer provides instant feedback which more quickly corrects students' encoding errors. The learners were also the only ones who could see the responses. As a result, students might not have had a fear of making mistakes. This fosters a low affective filter environment which aids language acquisition [53, 54]. The outcomes of this project were congruent with those of previous studies $[1,6,10,27,44-46]$, which found that using a computer to learn L2 vocabulary can be beneficial and effective.

The findings of this study corroborated Nakata's [55] remarks that computerized flashcards, which can present words with multiple cues, feedback, and clue affordance, enhance the learning process. This could be rationalized as that when flashcards are designed and presented in a computerized environment or used in space distribution presentation, a high speed of retrieval is facilitated.

Moreover, it agrees with the finding of Ashcroft et al. [56] that students who have been exposed to computerized flashcards can achieve higher L2 vocabulary gains especially when they have low-level proficiency since they benefit from the multimedia affordances of the application and the agency fostered through learner autonomy.

The results of this project also accorded with those of Pedro et al. [11], who suggested that because of its widespread usage, MALL as a CALL extension, may have beneficial impacts in learning situations. They note that, through the use of CALL-enhanced L2 vocabulary applications, student's engagement and motivation in mobile or computer-assisted language learning contents can be accelerated.

The results are also reflective of Mahdi's [25] study which indicates that mobile vocabulary learning can be more efficient than mass-learning using paper. He assumes that this achievement can be attributed to the quick access of students to the mobile screen, which results in near constant exposure and more regular practice of vocabulary content. The results of this analysis also correspond with Naraghizadeh and Barimani's findings [57]. Their findings indicate a substantial variation in their L2 vocabulary skills among the EG and CG. The researchers found that the members of the EG performed better, and their scoring was higher than that of the CG. The obtained results are also confirmed by Ahmadian et al. [58] and Taki and Jafari [46], who observed that the group who used software showed greater improvement in L2 vocabulary learning than the other group who were exposed to traditional paper-based L2 vocabulary learning.

This research indicates that the use of Mnemosyne tools to teach vocabulary elements would improve EFL students' learning performance. Mnemosyne has expanded learners' motivation for learning vocabulary and allows students to experience various forms of vocabulary learning, with Mnemosyne students actively participated in the learning process by engaging in immersive games and tasks to develop their vocabulary. Based on these successes, more chances should be provided for EFL students to communicate in their classrooms with the use of a visual vocabulary training platform like the one examined in this report [46]. To sum up, this research supports findings that CALL-based language training exercises have a significant positive impact on the language learning of EFL learners. EFL students benefitted more from class time by participating in constructive and interesting assignments during their training exercises.

What should also be considered is that, with applying mobile apps for personal learning tools by students in particular, MALL can revolutionize language learning in general and that the usefulness of mobile learning relies largely on whether mobile technology is available, accepted and considered valuable by both students and instructors. This should be considered when making decisions on design and presentation when constructing MALL courseware or materials. This research may also help inform linguistic teachers and managers when choosing the most suitable L2 vocabulary learning MALL services. Finally, we expect that mobile learning will help anyone who wants to study a variety of subject matters including math, geography, and biology. The affordances provided by MALL such as visuals, feedback, or note-taking features of the software and interaction designs, if developed sufficiently well, can enable learners improve their engagement and performance in learning processes whatever the subject matter.

The study's shortcomings, as well as our thoughts, provoke ideas for future studies. Based on the study's limitations, it is suggested that the sample size of participants must be increased to yield more generalizable and solid findings in future studies, and also researchers should develop a program to track L2 learners' time on-task and capture data reflective of their pattern of learning new words for each of the situations under consideration. This could reveal correlations between exposure, time-on task, and achievement.

In summary, after examining the investigations, the researcher explored congruence with numerous other researchers who corroborate the utility CALL incorporation in language acquisition in L2 skills and L2 vocabulary development. The current study indicates that CALL implementation in vocabulary learning is more effective for students than other more traditional approaches. This concurs with researchers in the majority of previous studies who have strongly advocated for the utilization of CALL in learning L2 vocabulary. Computers may also be used to enhance other dimensions of L2 vocabulary awareness. Lastly, in this research, posttests investigated the immediate acquisition of lexical objects by learners. Further experiments are proposed to assess the long-term acquisition of vocabulary through conducting a subsequent posttest in following semesters. 


\section{Data Availability}

The data that support the findings of this study are available from the corresponding author upon reasonable request.

\section{Conflicts of Interest}

The authors declare that they have no conflicts of interest.

\section{References}

[1] M. Taghizadeh and Z. Hasani Yourdshahi, "Integrating technology into young learners' classes: language teachers' perceptions," Computer Assisted Language Learning, vol. 33, no. 8, pp. 982-1006, 2020.

[2] L. Darling-Hammond, L. Flook, C. Cook-Harvey, B. Barron, and D. Osher, "Implications for educational practice of the science of learning and development," Applied Developmental Science, vol. 24, no. 2, pp. 97-140, 2020.

[3] R. González-Carriedo and P. Esprívalo Harrell, "Teachers' attitudes toward technology in a two-way dual-language program," Computers in the Schools, vol. 35, no. 2, pp. 111-133, 2018.

[4] P. I. Lavalle and M. Briesmaster, "The study of the use of picture descriptions in enhancing communication skills among the 8th-grade students-learners of English as a foreign language," Inquiry in Education, vol. 9, no. 1, pp. 1-20, 2017.

[5] P. Hubbard, "CALL and the future of language teacher education," CALICO Journal, vol. 25, pp. 175-188, 2008.

[6] H. Tabar and M. Khodareza, "The effect of using multi-media on vocabulary learning of pre-intermediate and intermediate Iranian EFL learners," Journal of Basic and Applied Research, vol. 2, no. 12, pp. 12879-12891, 2012.

[7] B. Gorjian, S. R. Moosavinia, K. Ebrahimi Kavari, P. Asgari, and A. Hydarei, "The impact of asynchronous computerassisted language learning approaches on English as a foreign language high and low achievers' vocabulary retention and recall," Computer Assisted Language Learning, vol. 24, no. 5, pp. 383-391, 2011.

[8] P. Hubbard, Computer Assisted Language Learning: Critical Concepts in Linguistics, Routledge, London, UK, 2009.

[9] P. Macaruso and A. Rodman, "Benefits of computer-assisted instruction to support reading acquisition in English language learners," Bilingual Research Journal, vol. 34, no. 3, pp. 301-315, 2011.

[10] N. Shokrpour, Z. Mirshekari, and S. Moslehi, "Learning vocabulary electronically: does computer assisted language learning (CALL) instruction have any impacts on Iranian EFL learners?" Cogent Education, vol. 6, no. 1, pp. 1-20, 2019.

[11] L. F. M. G. Pedro, C. M. M. Barbosa, and C. M. Santos, “A critical review of mobile learning integration in formal educational contexts," International Journal of Educational Technology in Higher Education, vol. 15, no. 10, pp. 1-15, 2018.

[12] A. Sulaimani, P. Sarhandi, and M. Buledi, "Impact of CALL in-house professional development training on teachers' pedagogy: an evaluative study," Cogent Education, vol. 4, no. 1, pp. 1-12, 2017.

[13] M. Celce-Murcia, Teaching English as a Second or Foreign Language, Heinle \& Heinle Publishers, Boston, MA, USA, 2002.

[14] J. Xu, "On the problems and strategies of multimedia technology in English teaching," Journal of Language Teaching and Research, vol. 1, no. 3, pp. 215-218, 2010.
[15] M. Manasreh, "Scaffolding listening through ICT with young learners in Qatar," in International Perspectives on Teaching English to Young Learners, S. Rich, Ed., Palgrave McMillan, London, UK, 2014.

[16] S. A. Ostovar-Namaghi and A. Malekpur, "Vocabulary learning strategies from the bottom-pp: a grounded theory," The Reading Matrix: An International Online Journal, vol. 15, no. 2, pp. 235-251, 2015.

[17] Y. Hsieh, "Effects of video captioning on EFL vocabulary learning and listening comprehension," Computer Assisted Language Learning, vol. 33, no. 5-6, pp. 567-589, 2020.

[18] P. Wright, Pictures for Language Learning, Cambridge University Press, Cambridge, UK, 1992.

[19] K. Ciampa, "Learning in a mobile age: an investigation of student motivation," Journal of Computer Assisted Learning, vol. 30, no. 1, pp. 82-96, 2014.

[20] H. Crompton, D. Burke, and K. H. Gregory, "The use of mobile learning in PK-12 education: a systematic review," Computers \& Education, vol. 110, pp. 51-63, 2017.

[21] R. Godwin-Jones, "Smartphones and language learning," Language, Learning and Technology, vol. 21, no. 2, pp. 3-17, 2017.

[22] E. Chukharev-Hudilainen and T. A. Klepikova, "The effectiveness of computer-based spaced repetition in foreign language vocabulary instruction: a double-blind study," CALICO Journal, vol. 33, no. 3, pp. 18-40, 2016.

[23] N. Fallows, "A flipped approach to vocabulary teaching in HCT Dubai colleges foundations level 03: utilizing spaced repetition for consolidation," UAE Journal of Education Technology and eLearning, vol. 4, no. 1, pp. 35-39, 2013.

[24] M. Gómez-García, R. Soto-Varela, J. A. Morón-Marchena, and M. J. Pino-Espejo, "Using mobile devices for educational purposes in compulsory secondary education to improve student's learning achievements," Sustainability, vol. 12, pp. 1-12, 2020.

[25] H. S. Mahdi, "Effectiveness of mobile devices on vocabulary learning: a meta-analysis," Journal of Educational Computing Research, vol. 56, no. 1, pp. 134-154, 2018.

[26] T. Nakata, "Computer-assisted second language vocabulary learning in a paired-associate paradigm: a critical investigation of flashcard software," Computer Assisted Language Learning, vol. 24, no. 1, pp. 17-38, 2011.

[27] X.-L. Pham, G.-D. Chen, T.-H. Nguyen, and W.-Y. Hwang, "Card-based design combined with spaced repetition: a new interface for displaying learning elements and improving active recall," Computers \& Education, vol. 98, no. 3, pp. 142-156, 2016.

[28] J. R. Calvo-Ferrer, "Educational games as stand-alone learning tools and their motivational effect on L2 vocabulary acquisition and perceived learning gains," British Journal of Educational Technology, vol. 48, no. 2, pp. 264-278, 2017.

[29] C.-M. Chen, H. Liu, and H.-B. Huang, "Effects of a mobile gamebased English vocabulary learning app on learners' perceptions and learning performance: a case study of Taiwanese EFL learners," ReCALL, vol. 31, no. 2, pp. 170-188, 2019.

[30] Y. Zhonggen, "Differences in serious game-aided and traditional English vocabulary acquisition," Computers \& Education, vol. 127, pp. 214-232, 2018.

[31] E. Namaziandost, M. Nasri, F. R. Esfahani, and M. H. Keshmirshekan, "The impacts of spaced and massed distribution instruction on EFL learners' vocabulary learning," Cogent Education, vol. 6, no. 1, 2019.

[32] E. Y. Sitompul, "Teaching vocabulary using flashcards and word list," Journal of English and Education, vol. 1, no. 1, pp. 52-58, 2013. 
[33] M. Lessard-Clouston, Teaching Vocabulary, TESOL International Association, Alexandria, VA, USA, 2013.

[34] E. Peters, "The effect of imagery and on-screen text on foreign language vocabulary learning from audiovisual input," TESOL Quarterly, vol. 53, no. 1, pp. 1-12, 2019.

[35] R. Goodfellow, "Design principles for computer-aided vocabulary learning," Computers \& Education, vol. 23, no. 1-2, pp. 53-62, 1994.

[36] C. Kirsch, "Using storytelling to teach vocabulary in language lessons: does it work?" The Language Learning Journal, vol. 44, no. 1, pp. 33-51, 2016.

[37] T. Ghorbani and S. Jahandar, "The Effect of-learning on Iranian Intermediate EFL learners' word retention," International Research Journal of Applied and Basic Sciences, vol. 9, no. 7, pp. 103-106, 2015.

[38] Y.-M. Huang and Y.-M. Huang, "A scaffolding strategy to develop handheld sensor-based vocabulary games for improving students' learning motivation and performance," Educational Technology Research \& Development, vol. 63, no. 5, pp. 691-708, 2015.

[39] S. Khezrlou and K. Sadeghi, "Glossing mode in self-regulated vocabulary learning, and its relationship with gender, age, and field of study," The Journal of Asia TEFL, vol. 9, no. 3, pp. 51-74, 2012.

[40] E. Namaziandost, S. Alekasir, E. Saberi Dehkordi, and S. Ahmad Tilwani, “An account of EFL learners' vocabulary learning in a mobile-assisted language environment: the case of Rosetta Stone application," Computer-Assisted Language Learning Electronic Journal (CALL-EJ), vol. 22, no. 1, pp. 801-810, 2021.

[41] J. Li, J. Cummins, and Q. Deng, “The effectiveness of texting to enhance academic vocabulary learning: English language learners' perspective," Computer Assisted Language Learning, vol. 30, no. 8, pp. 816-843, 2017.

[42] P. Nation, Learning Vocabulary in Another Language, CUP, Cambridge, UK, 2001.

[43] W. E. Nagy, R. C. Anderson, and P. A. Herman, "Learning word meanings from context during normal reading," American Educational Research Journal, vol. 24, no. 2, pp. 237-270, 1987.

[44] C. Altıner, "Integrating a computer-based flashcard program into academic vocabulary writing," TOJET, vol. 18, no. 1, pp. 44-62, 2019.

[45] S. McLean, N. Hogg, and T. W. Rush, "Vocabulary learning through an online computerized flashcard site," The JALT CALL Journal, vol. 9, no. 1, pp. 79-98, 2013.

[46] S. Taki and S. Jafari, "The impact of Mnemosyne computer software on Iranian EFL learners' vocabulary learning," The Journal of Applied Linguistics and Applied Literature: Dynamics and Advances, vol. 5, no. 2, pp. 101-111, 2017.

[47] L. Allen, The Oxford Placement Test, Oxford University Press, Oxford, UK, 2004.

[48] S. K. Carpenter, N. J. Cepeda, D. Rohrer, S. H. K. Kang, and H. Pashler, "Using spacing to enhance diverse forms of learning: review of recent research and implications for instruction," Educational Psychology Review, vol. 24, no. 3, pp. 369-378, 2012.

[49] C. Browne, B. Culligan, and J. Phillips, http://www. newgeneralservicelist.org/nawl-new-academic-word-list New academic word list., 2013.

[50] H. Reinders and C. White, "The theory and practice of technology in materials development and task design," in English Language Teaching Materials: Theory and Practice,
N. Harwood, Ed., pp. 58-80, Cambridge University, Cambridge, UK, 2011.

[51] Y. Yelbay Yilmaz, "Learning vocabulary in a foreign language: a computer software-based model attempt," Journal of Language and Linguistic Studies, vol. 11, no. 2, pp. 23-38, 2015.

[52] F. Kilıckaya and J. Krajka, "Comparative usefulness of online and traditional vocabulary learning," The Turkish. Online Journal of Educational Technology, vol. 9, no. 2, pp. 55-63, 2010.

[53] T. Basöz and D. T. Can, "The effectiveness of computers on vocabulary learning among preschool children: a semiotic approach," Cypriot Journal of Educational Sciences, vol. 11, no. 1, pp. 02-08, 2016.

[54] S. Krashen, Principles and Practice in Second Language Acquisition, Pergamon Press, Oxford, UK, 1982.

[55] T. Nakata, "Learning words with flash cards and word cards," in The Routledge Handbook of Vocabulary Studies, S. Webb, Ed., pp. 304-319, Routledge, New York, NY, USA, 2019.

[56] R. Ashcroft, C. McMillan, W. Ambrose-Miller, R. McKee, and J. B. Brown, "The emerging role of social work in primary health care: a survey of social workers in Ontario Family Health teams," Health \& Social Work, vol. 43, no. 2, pp. 109-117, 2018.

[57] M. Naraghizadeh and S. Barimani, "The effect of CALL on the vocabulary learning of Iranian EFL learners," Journal of Academic and Applied Studies, vol. 3, no. 8, pp. 1-12, 2013.

[58] M. Ahmadian, M. Amerian, and A. Goodarzi, "A Comparative study of paper-based and computer-based contextualization in vocabulary learning of EFL students," Advances in Language and Literary Studies, vol. 6, no. 2, pp. 96-102, 2015. 